\title{
Rho Guanine Nucleotide Exchange Factor 7
}

National Cancer Institute

\section{Source}

National Cancer Institute. Rho Guanine Nucleotide Exchange Factor 7. NCI Thesaurus. Code C97202.

Rho guanine nucleotide exchange factor 7 ( $803 \mathrm{aa}, \sim 90 \mathrm{kDa}$ ) is encoded by the human ARHGEF7 gene. This protein plays a role in both the modulation of small GT Pase activity and the induction of apoptosis. 